\title{
Application of infrared technique in soil properties' characterization in South Kivu province of DR Congo
}

\author{
Bashagaluke Janvier $^{1,2,4}$, Nshobole Nicole ${ }^{1}$, Fataki Didier ${ }^{3}$, Mochoge Benson ${ }^{2}$, Mugwe \\ Jayne $^{2}$, Walangululu Jean ${ }^{1}$ \\ ${ }^{1}$ Université Catholique De Bukavu (UCB), DR Congo \\ ${ }^{2}$ Kenyatta University, Nairobi, Kenya \\ ${ }^{3}$ Institut Supérieur d'Informatique et de Gestion (ISIG-Goma). \\ ${ }^{4}$ Institut Supérieur des Techniques de Développement de Kalehe ISTD/Kalehe \\ Corresponding author's e-mail: bashbigabwa@yahoo.fr
}

ABSTRACT

\begin{abstract}
Understanding soil properties is an essential pre-requisite for sustainable land management. Assessment of soil properties has long been done through conventional laboratory analysis, which is costly and time consuming. Therefore, there is a need to develop alternative cheaper and faster techniques for soil analysis. In recent years, special attention has been given to Infrared Reflectance Spectroscopy and chemometrics. Near Infrared Reflectance (NIR) and mid-infrared (MIR) spectroscopy techniques are rapid, convenient and simple non-destructive techniques for quantifying several soil properties. This study aims to characterized soil based on based on infrared spectroscopy. This method were to predict soil $\mathrm{pH}$, soil organic $\mathrm{C}$, total $\mathrm{N}$, exchangeable $\mathrm{Al}, \mathrm{Ca}, \mathrm{Mg}$, and $\mathrm{K}$, CEC and soil texture for soil samples collected in Sud-Kivu province, Democratic Republic of Congo. A total of 530 composite soil samples were taken from two locations (Burhale and Luhihi) at two depths (0-20 and 20$40 \mathrm{~cm}$ ) using a spatially-stratified random sampling design within an area of $100 \mathrm{~km}^{2}$. After minimal sample preparation, the MIR spectrum of a soil takes about two minutes for the analyses. Ddifferences in characteristics were evaluated between the two locations, land use (cultivated vs. non-agricultural land) and soil depth. A random subset of the samples (10\%) were analyzed using standard wet chemistry methods, and calibration models developed using MIR data to estimate soil properties for the full soil sample set. Partial least squares regression (PLS) method gave acceptable coefficients of determination between 0.71 and 0.93 for all parameters hence good prediction. Though IR is cheap for analyzing soil properties it requires high investment at the beginning. There is therefore need of technical and material support to make this technology useful in developing countries.
\end{abstract}

Key word: spectroscopy, prediction, regression, soil nutrient, infrared

\section{INTRODUCTION}

Soil fertility decline is a major cause of food insecurity in the world. The lack of specific information on soil management and sustainability at farm level reduce the soil productivity since farmers are not able to use adequate techniques for yield improvement. Most of the information related to nutrient content in the soil is not available and at the same time most of the research centres do not have adequate equipments for undertaking research. Laboratory costs for soil analysis are very high and unaffordable to majority of the farmers. The current methods (wet chemistry) of soil analysis in most research centres take long to avail results in good time due to many processes involved. The need, for sustainable and rapid techniques of soil analysis to improve fertilizer use to increase agricultural productivity is urgent particularity in SSA where soil fertility depletion is more pronounced. Numerous studies have demonstrated the effectiveness of MIR in performing quantitative analysis of soils, including soil carbon (Reeves et al., 1999; Shepherd and Walsh, 2002; Christy, 2009). Many of the properties predicted from MIR spectra are those that generally change only slowly in 


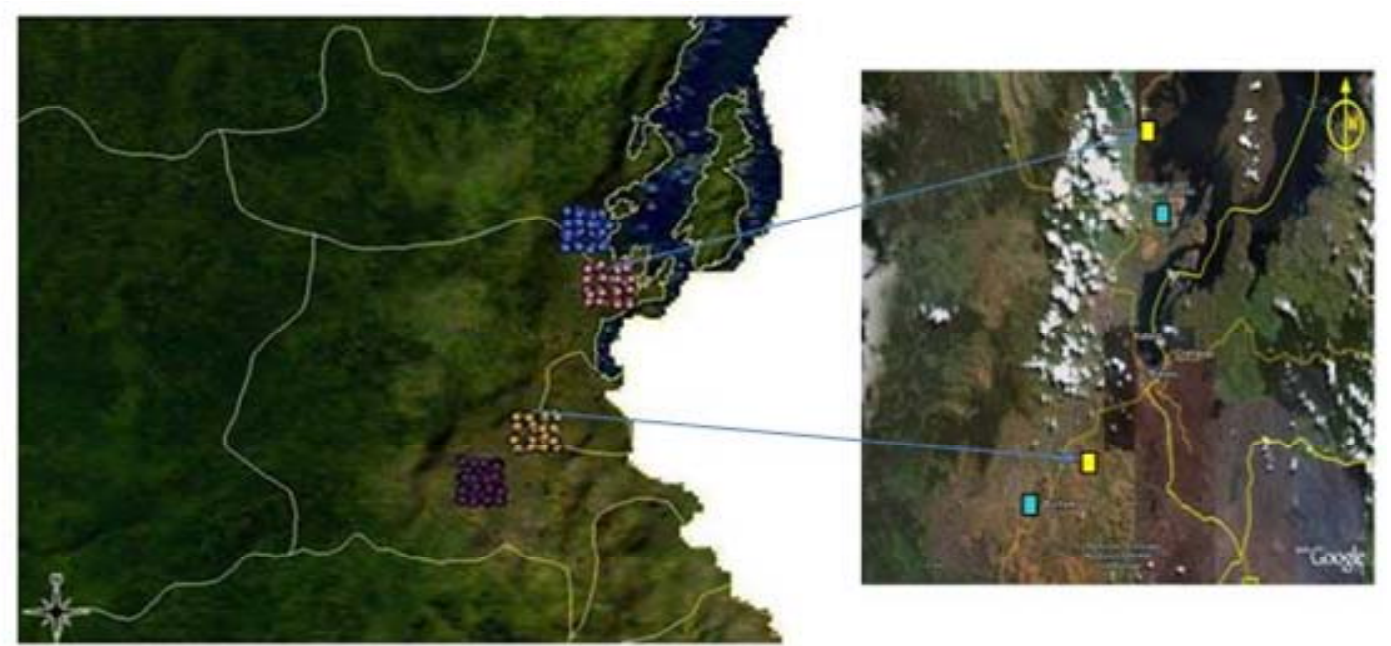

Figure 1. the Study area with the two sites: Burhale and Luhihi

soils so that, once analyzed, re-analysis for that property may not be required, or only after a long time interval. A detailed study of the role of many soil physical, chemical and biological properties in terrestrial ecosystems demands less expensive and faster data acquisition techniques to quantify the different soil properties. This is especially true for precision agriculture and other applications where precise spatial resolution of soil properties is required. Recent studies have shown the possibility of using infrared reflectance spectroscopy and multivariate chemometrics in order to obtain qualitative and quantitative assessment of some chemical and physical parameters of the soil rapidly and at low cost Therefore, infrared spectral analyses are ideally suited for soil resources inventory (Minasny et al, 2008). Infrared reflection (IR) spectroscopy has attracted interest among soil scientists as a possible technique for improved soil analyses owing to rapid, non-destructive, cheap measurements as well as possibilities to determine several soil properties simultaneously. Now is capital to increase productivity by investing in soil health Farmers in SSA lack information on soil fertility management even from extension services or research institutes that can help them understand the health of their soil. Infrared is a new method of soil analysis that is rapid and inexpensive but needs to be validated as before it is recommended for wide use. There is currently scanty data to show its accuracy and hence limited applicability for use in making land management decisions. The purpose of this study is therefore to assess the accuracy of this new method as well as use the results to analyze differences in soils sampled from different areas.

\section{MATERIALS AND METHODS}

The study was conducted in the eastern region DRC within South Kivu province. This region is characterized by highland features with a very high population density and high rain fall (Farrow et al., 2006). Burhale and Luhihi are the two site selected for this study as shown on figure 1.

Overpopulation causes the soils in South-Kivu to become impoverished through erosion and nutrient mining that also causes decreased land area for livestock production resulting in a reduction in the number of animals able to provide the farmers with manure (DSRP, 2005).

The main activity in the region is agriculture. Traditional livestock comprises of cattle, sheep, goats, chicken and pigs. The biggest zone of animal production in South-Kivu is located in the plain of Uvira. In Burhale (Walungu) and Luhihi (Kabare), on the other hand, number of cattle has decreased due to decreasing grazing space as a result of overpopulation. In addition, big plantations of tea, coffee and quinquina can be found in the area (Mateso et al., 1998). Soil types in South-Kivu are diverse, and mainly determined by their geological parent material (Mateso, 1998). Based on the parent material, the soils of South-Kivu can be subdivided into four major groups:

1. Soils that have recently formed on volcanic substrate;

2. Soil developed on old volcanic substrate, mainly basaltic ;

3. Soils formed on old sedimentary and metamorphic rocks (cover extensive areas) and,

4. Alluvial soils and lacustrin and fluviatile deposits of the plains of Rusizi.

All the 530 Samples collected were subjected to IR scanning using infrared reflectance spectra in the range of 400 to $7000 \mathrm{~cm}-1$. Only a few grams of soil were obtained for the samples (approximately 20 to $30 \mathrm{mg}$ ). Air-dried samples were finely ground to powder (approximately $\mathrm{N}<100 \mu \mathrm{m}$ ), using an agate pestle and mortar. The samples were loaded into aluminum micro 


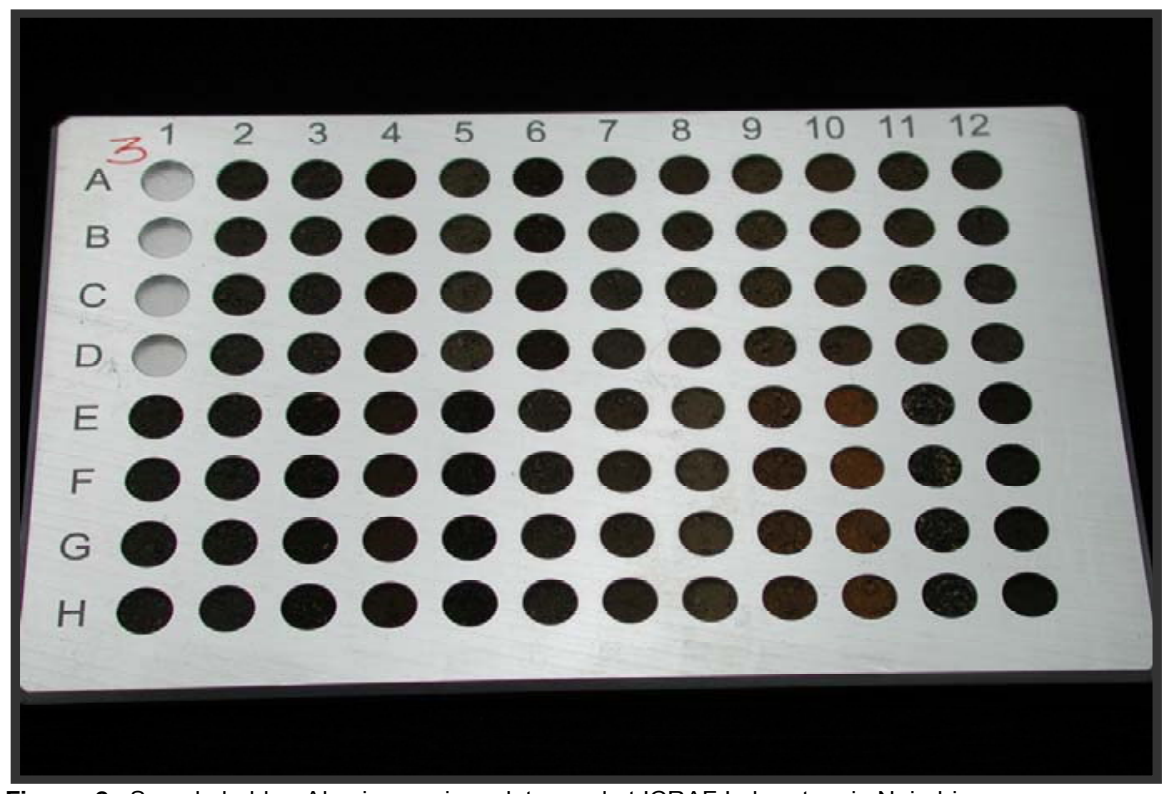

Figure 2 . Sample holder: Aluminum micro plate used at ICRAF Laboratory in Nairobi

titer plates using a micro spatula to fill the 6-mm-diameter wells and level the soil by taking care to avoid spillage into neighboring wells; The plate had a total of 96 wells; an empty well was used to measure background signal ( Figure 2) ( ICRAF, 2009,). Background measurements of the first empty well were taken before each single measurement to account for changes in temperature and air humidity (Mevik and Wehrens, 2007). Aluminum is suitable as a reference material because it does not absorb infrared light (Terhoeven et al., 2010). The bottoms of the Al wells were roughened to minimize specular reflectance. Soil samples were loaded into four replicate wells, each scanned 32 times (figure 2), and the four spectra averaged to account for within-sample variability and differences in particle size and packing density.

Only 60 samples (around $10 \%$ the 530 samples collected as recommended by AFSIS) were analyzed using wet chemical analysis according to AFSIS approach (Vagen et al 2010). This means that the 60 samples were analyzed twice: by scanning and by wet chemistry.

The quality of prediction was determined by using PLS (partial least squares regression) model that combine the two data type for the prediction (Næs et al, 2002). For the measured values and estimated values, the coefficient of regression $\left(R^{2}\right)$ and root mean square deviation (RMSD) (Tillmann, 2000; Brown et al.2005) were used to access the quality of the prediction. Calculations and statistical analysis were done using $\mathrm{R}$ soft ware version 2.7.1 (R Development Core Team, 2008). For interpretation the high $R^{2}$ and low RMSD show that, the calibration and prediction were good; the estimated values are closer to true values that have been measured by direct wet chemistry. Good predictions for such a diverse data set are regarded as having an $\mathrm{R}^{2}$ $\geq 0.75$ (Shepherd and Walsh, 2002; Chang et al., 2001), Satisfactory predictions have an $\mathrm{R}^{2}$ from 0.65 to 0.75 and predictions below those values were considered to be poor, (Shepherd and Walsh, 2002; Chang et al., 2001; Terhoeven et al, 2010).

The root mean square deviation (RMSD) was determined using the following formula according to Brown et al.(2005):

$\mathrm{RMSD}=\sqrt{\frac{\sum_{n}{\text { (Ypread }- \text { Ymeas }^{2}}^{2}}{N}}$

Where,

Ypread $=$ predicted value of the validation set using PLS model

Ymeas = the laboratory measurement of the validation

$\mathrm{N}=$ the total number of samples in the validation data

\section{RESULT AND DISCUSSION}

\section{Soil parameters prediction}

\section{Soil organic carbon}

Soil organic $C$ was well predicted for the validation set $\left(R^{2}=0.72\right.$ and RMSE = 1.07; (Figure 4.1. $)$. This shows that the prediction for this parameter was good. This finding agrees with other soil studies (Barthe et al. 2008; Ludwig et al. 2008). The results also agree with those of Rossel et al. (2006) who reported similar accuracy $\left(R^{2}=\right.$ 0.73 ) for a much less diverse validation set of 118 samples from 18 ha agricultural field in Australia. 


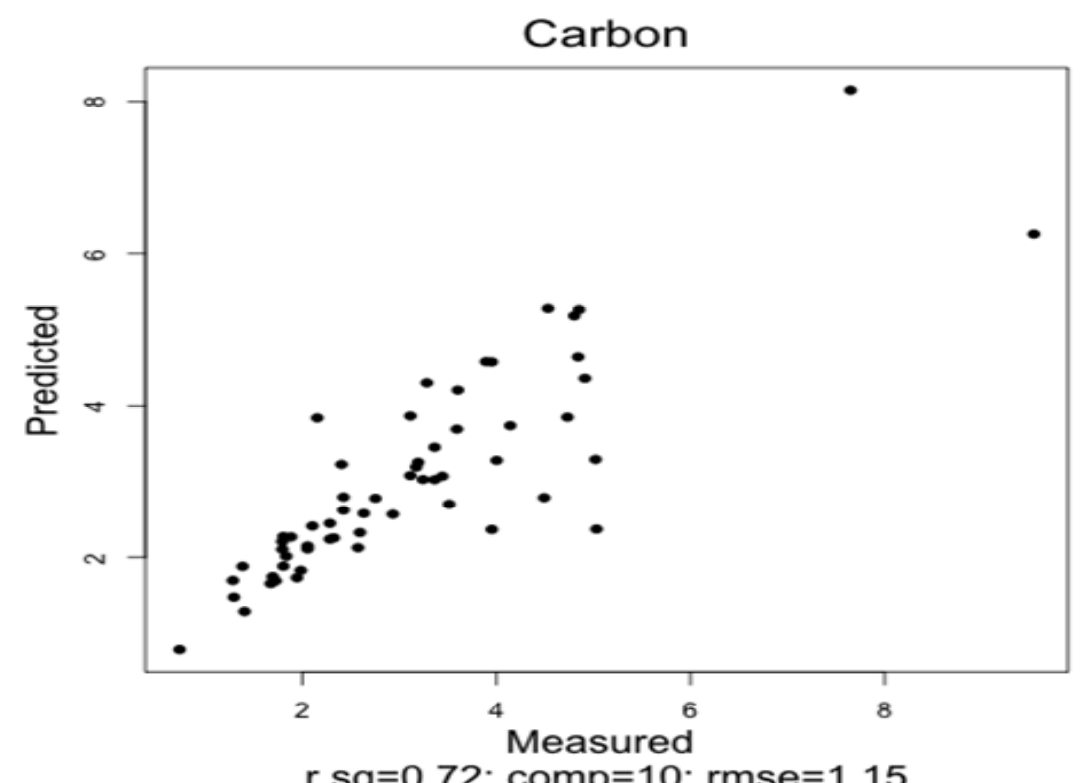

Figure 4.1. Correlation between measured and predicted values of soil organic $c$

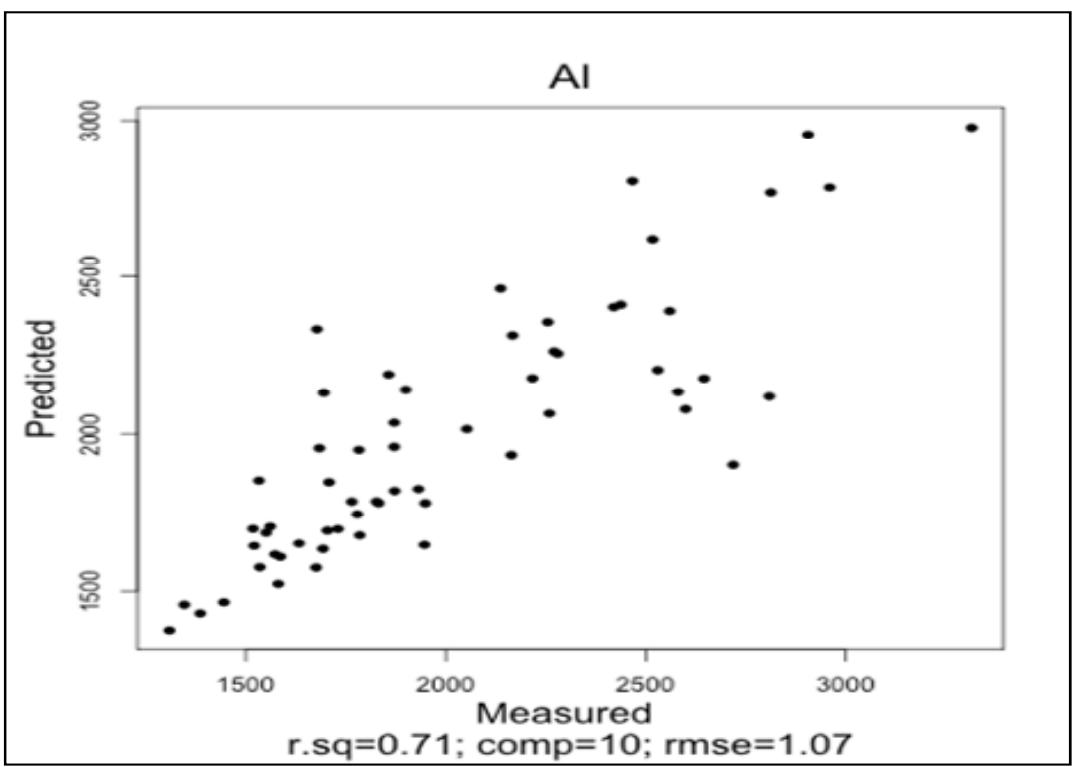

Figure 4.1 : Correlation between measured and predicted values of extractable $\mathrm{Al}$

Similarly, from a global study, Terhoeven et al. (2010) reported an $R^{2}=$ of 0.8 Soil organic carbon (SOC) is a key attribute of soil quality, which influences a variety of biological, chemical and physical properties of soils (Carter, 2002). Consequently, methods to accurately determine SOC are necessary to achieve a better understanding of the nature and dynamics of SOC (Denm8ef et al., 2009). Soil organic carbon is an indication of soil organic matter content, which acts as both a source and sinks for nutrients. Soil organic carbon is linked to soil chemical, physical and biological health, and is strongly correlated with soil nitrogen supply in term of soil fertility management. The satisfactory prediction of
SOC $\left(R^{2}<0.75\right)$ helps to monitor the soil status from the study area for a sustainable soil management. A study in Canada reported good prediction $\left(R^{2}=0.92\right)$ (Madari et al., 2006) than the current study. However, according to Shepherd and Walsh (2002) and Chang et al. (2001) predictions of $R^{2}$ ranging from 0.65 to 0.75 ) are satisfactory.

\section{Extractable Aluminum}

Extractable Aluminum was also well predicted $\mathrm{t}\left(R^{2}=0.71\right.$ and RMSE = 1.07 (Figure 4.2). 
62 Afr. J. Food Sci. Technol

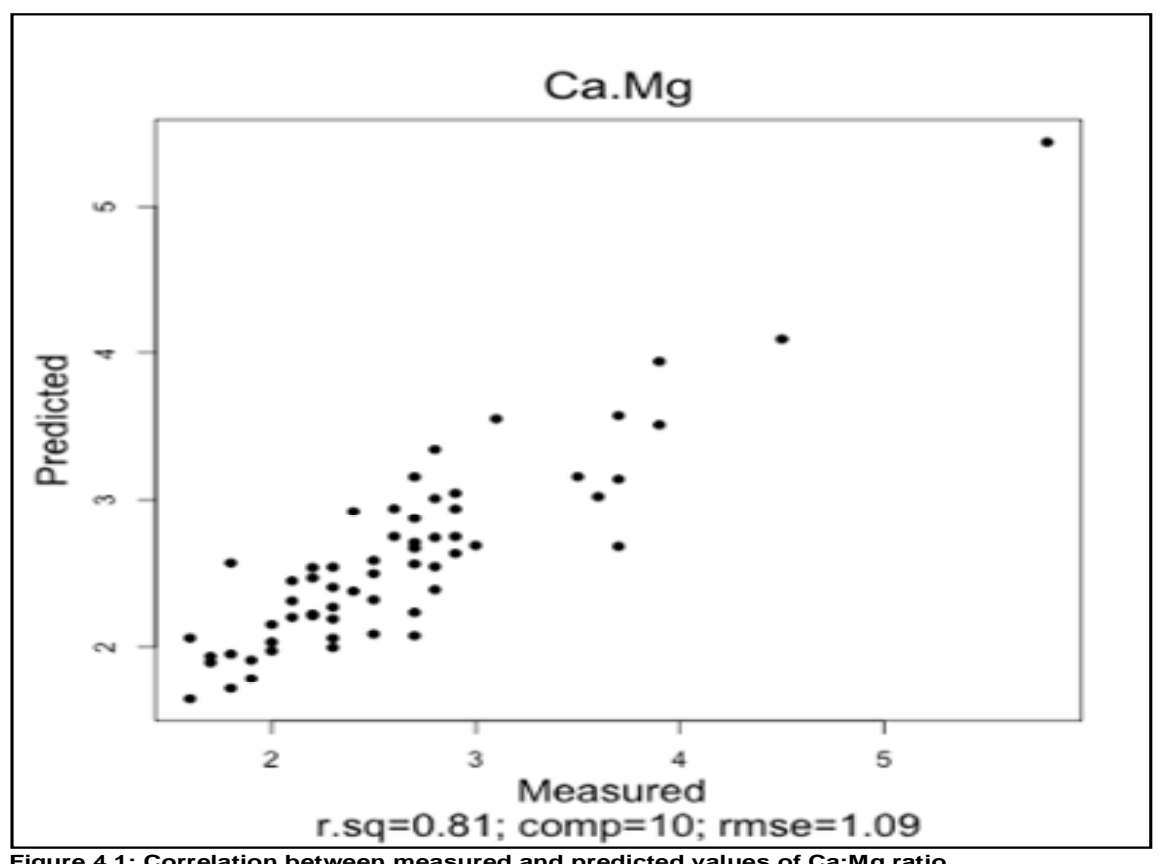

Figure 4.1: Correlation between measured and predicted values of Ca:Mg ratio

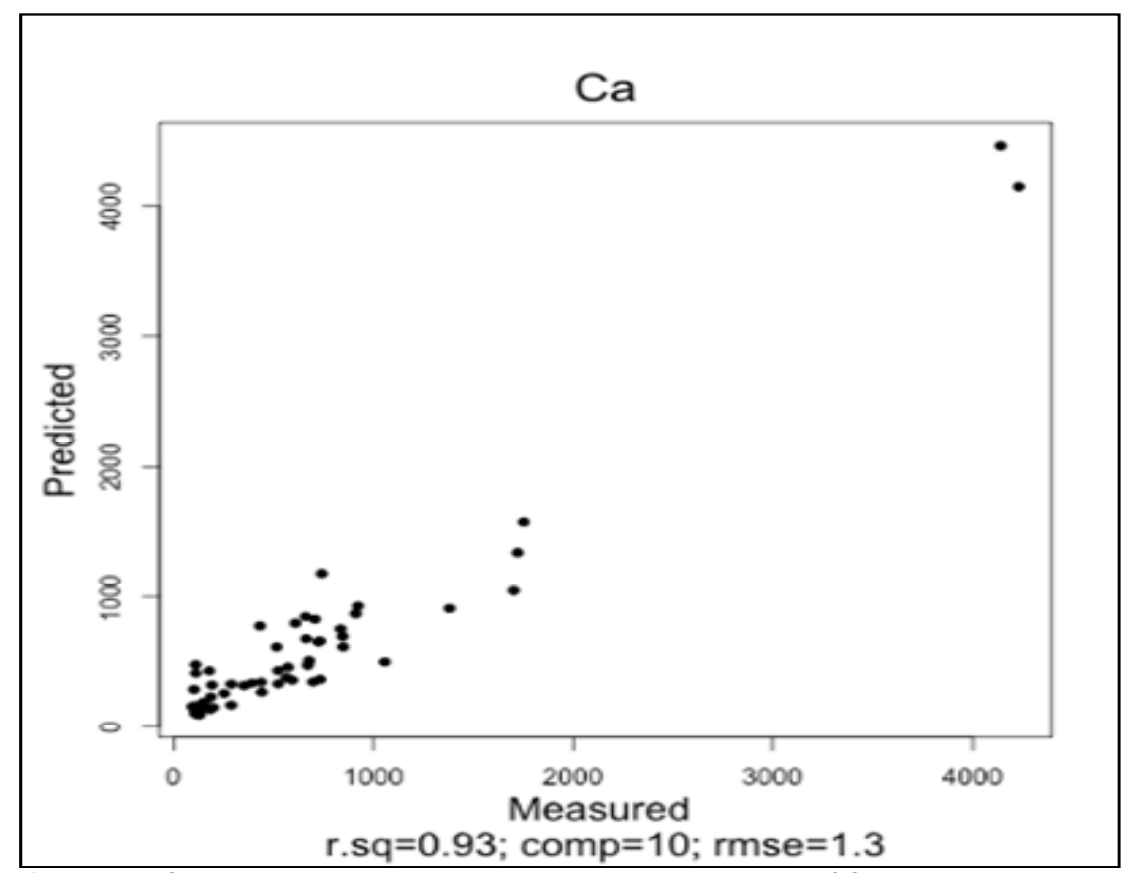

Figure 4.2: Correlation between measured and predicted values of $\mathrm{Ca}$ :Mg ratio

This shows good prediction of this parameter according to the standard of prediction provided (Terhoeven et al., 2010). Other studies reported an $\mathrm{R}^{2}$ of 0.71 (Brusetal, 2002; Borggaard et al., 2004). However, (Madari et al 2006) reported better prediction from his findings using Canadian soils $\left(R^{2}=88\right)$ than the current study may otherwise be lost from the soil rooting depth. Cheaper determinations of iron and aluminum oxide content will promote better phosphorus management and help alleviate nutrient pollution. The prediction of this parameter by the MIR gives a new area of monitoring soil fertility within the highlands of East of DRC.

\section{Calcium: Magnesium ratio}

The coefficient of correlation between actual measurements and predictions by PLS model for $\mathrm{Ca}: \mathrm{Mg}$ 


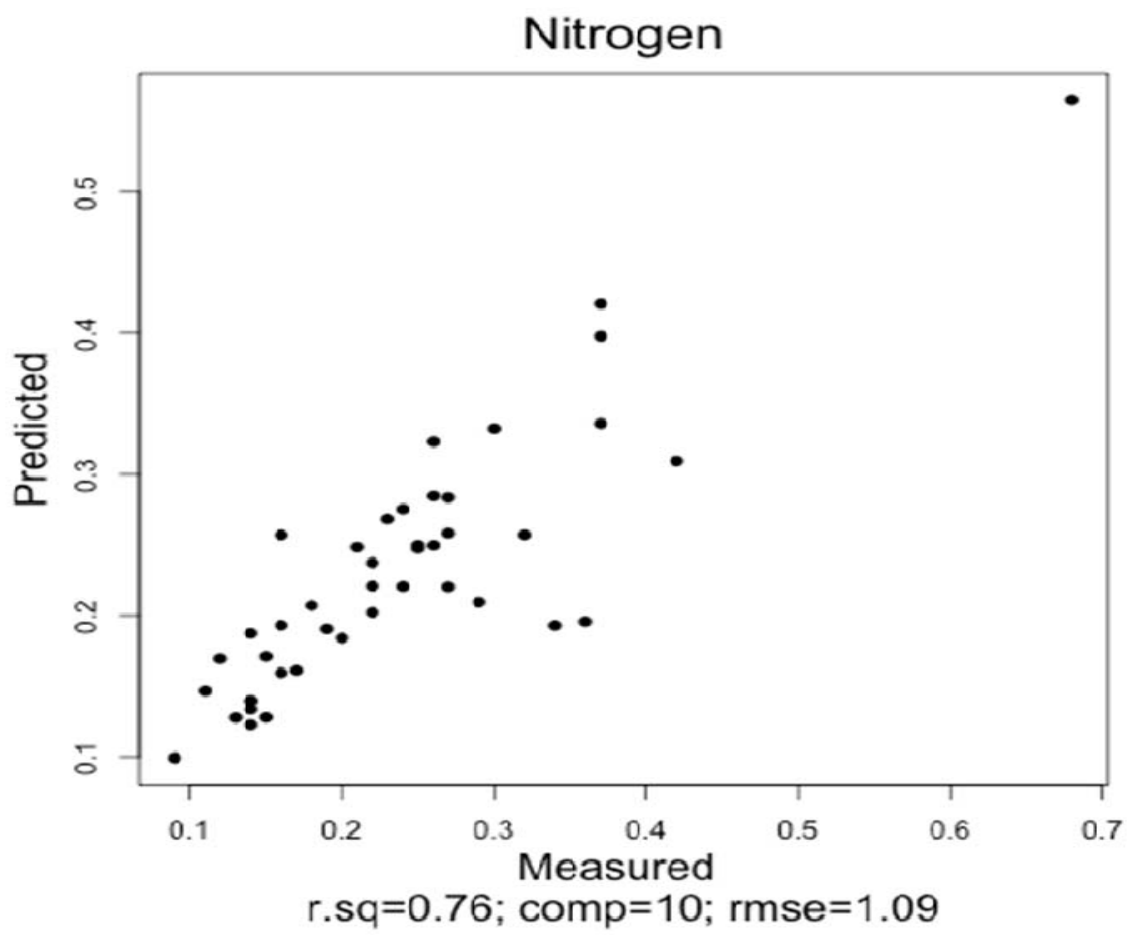

Figure4.3: Correlation between measured and predicted values of Total $\mathrm{N}$

ratio using the independent validation set of 60 samples was R2 of 0.81 (Figure 4.3).

The current study gave a better prediction $(R 2=0.81)$ than the results obtained in Australia (Minasny et al., 2009) of $R 2=0.30$ stating that MIR cannot predict the Ca:Mg accurately from that region. However, Dunn et al., 2002 obtained results that are showing the currency of $\mathrm{Ca} / \mathrm{Mg}$ ratio prediction $(\mathrm{R} 2=0.81)$ from the 178 samples collected from Canada which matches with the current study.

\section{Exactable Calcium}

Extractable calcium prediction was good as shown by the R2 values and RMSE (Figure 4.4). The coefficient of regression was high $(R 2=0.93)$ showing a good prediction of the parameter and therefore the validation of the model for the soil $\mathrm{Ca}$ analysis. This means $\mathrm{Ca}$ predicted within the current study might be used correctly for soil aptitude assessment according to the good model prediction.

Validation predictions for $\mathrm{Ca}$ for this study are better compared to results reported by several authors. For example, in a study carried out in the USA, McCarty and Reeves (2006) reported R2 of 0.77 for extractable calcium which is still lower compared to, current study.

Similary, Viscarra et al (2006) and McCarty and Reeves (2006) reported prediction values of R2 $=0.84$. Moreover, the model developed in the current study showed better results than those reported globally, for instance, by Terhoeven et al, 2010 who reported R2 =
0.61 and RMSE =1.64). This good prediction of $\mathrm{Ca}$, from the current study, is useful for the soil nutrient assessment and allows to recommend the use of IR scanning approach for this element.

\section{Total Nitrogen (TN)}

Total Nitrogen gave a good prediction regarding the R2 and the RMSE (Figure 4.5). The coefficient of regression of 0.76 shows an strong correlation between direct values and predicted values. This good prediction of TN gives an new option to assess this element in the soil easily. This is new opportunity of soil analysis of the most important soil nutrient for crop production in SSA gave new orientations of soil nutrient assessment.

These results agree with those reported by other authors; for example, Minasny et al. (2009) who reported the same ratio $(R 2=0.76)$ in a study conducted for Australian soils. Reeves et al. (2006); Cozzolino and Moro (2006); Barthe et al. (2008); and Vasques et al. (2009) reported the same value of R2=0.76 in studies carried out in regions with high agroecological variability. But the accuracy is still well since the prediction is good (R2>0.75) according to the standard. This means that the goodness for the prediction is also related on soil variability within the region. Therefore, that high calibration performance observed, from the study carried out from Canada, could be associated with the fact that the soil samples used were from the same area and belong to the same soil type (Reeves, 2006). 
64 Afr. J. Food Sci. Technol

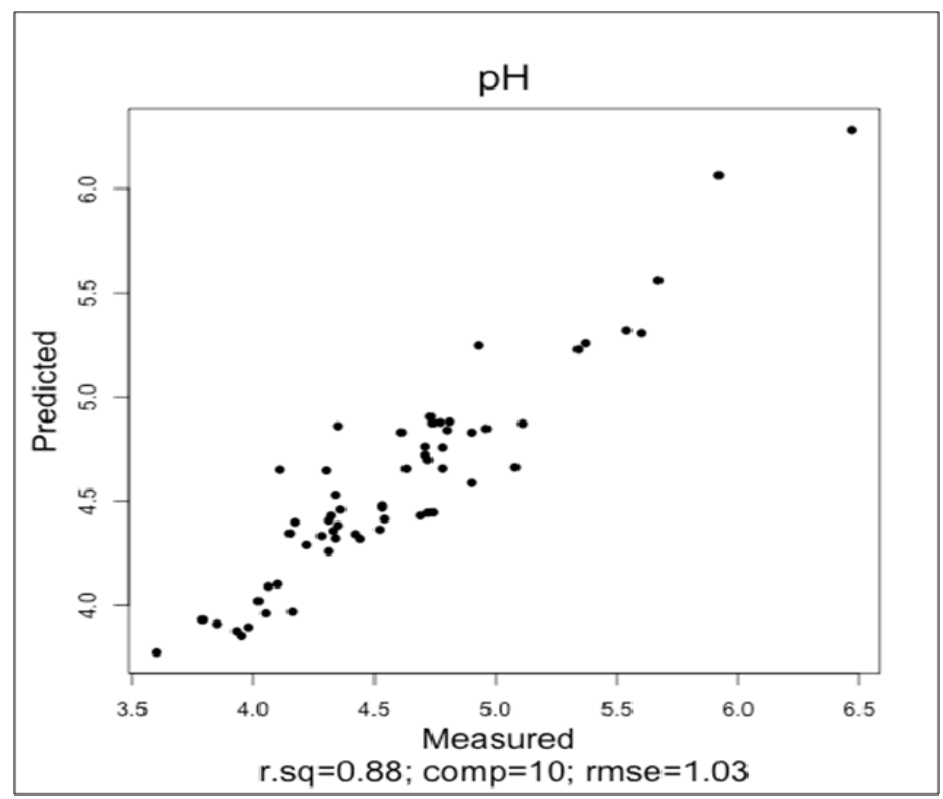

Figure 4.4: Correlation between measured and predicted values of $\mathrm{pH}$

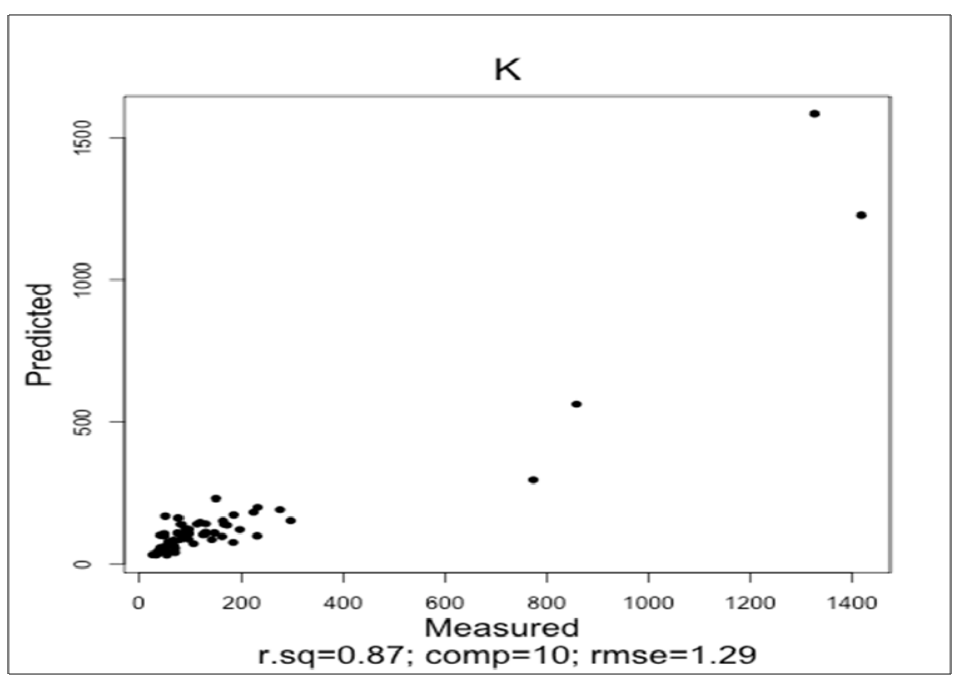

Figure 4.7: Correlation between measured and predicted values of extractable $\mathrm{K}$

\section{Soil pH}

Soil $\mathrm{pH}$ was predicted well with $\mathrm{R} 2=0.80$ and $\mathrm{RMSE}=$ 2.21 (Figure 4.6). These values correspond to those obtained by McCarty and Reeves (2006) for MIR analysis of 544 soil samples (272 locations) in one field from USA $(R 2=0.8)$. Similary, Terhoeven et al, (2010) got globally a value of $\mathrm{R} 2=0.8$ and $\mathrm{RMSE}=0.75$ in their study conducted in Australian landscape. Soil acidity is DRC's greatest land degradation problem, and is currently limiting agricultural production. Techniques that promote the measurement of soil $\mathrm{pH}$, the determination of the rate of lime required to achieve an acceptable $\mathrm{pH}$, and the quality of lime products, will greatly aid the management of soil acidity.
The results of the current study are slightly better than that obtained by Janik and Skjemstad (1995), who reported an R2 of value 0.72 (satisfactory prediction) for 291 Australian soils. Reeves (2009) indicated that the ability of infrared to predict $\mathrm{pH}$ is related to other factors such as organic acids and carbonates. According to these results of satisfactory prediction, this parameter has the potential to be predicted by MIR spectroscopy

\section{Extractable Potassium}

Extractable potassium was well predicted with the regression model having $\mathrm{R} 2=0.87$ (Figure 4.7).

These results show the goodness of spatial prediction of potassium within the study area. This good prediction 


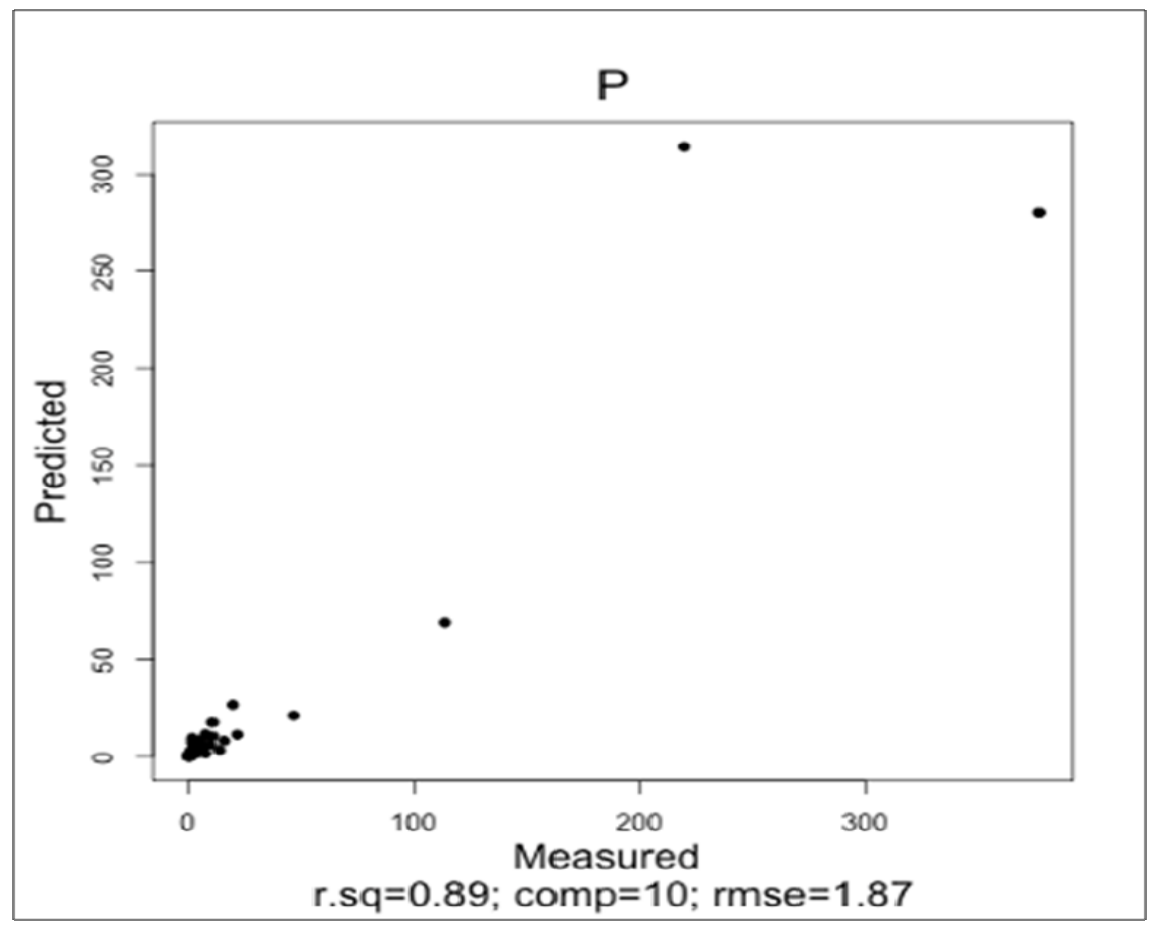

Figure 4.8: Correlation between measured and predicted values of extractable $P$

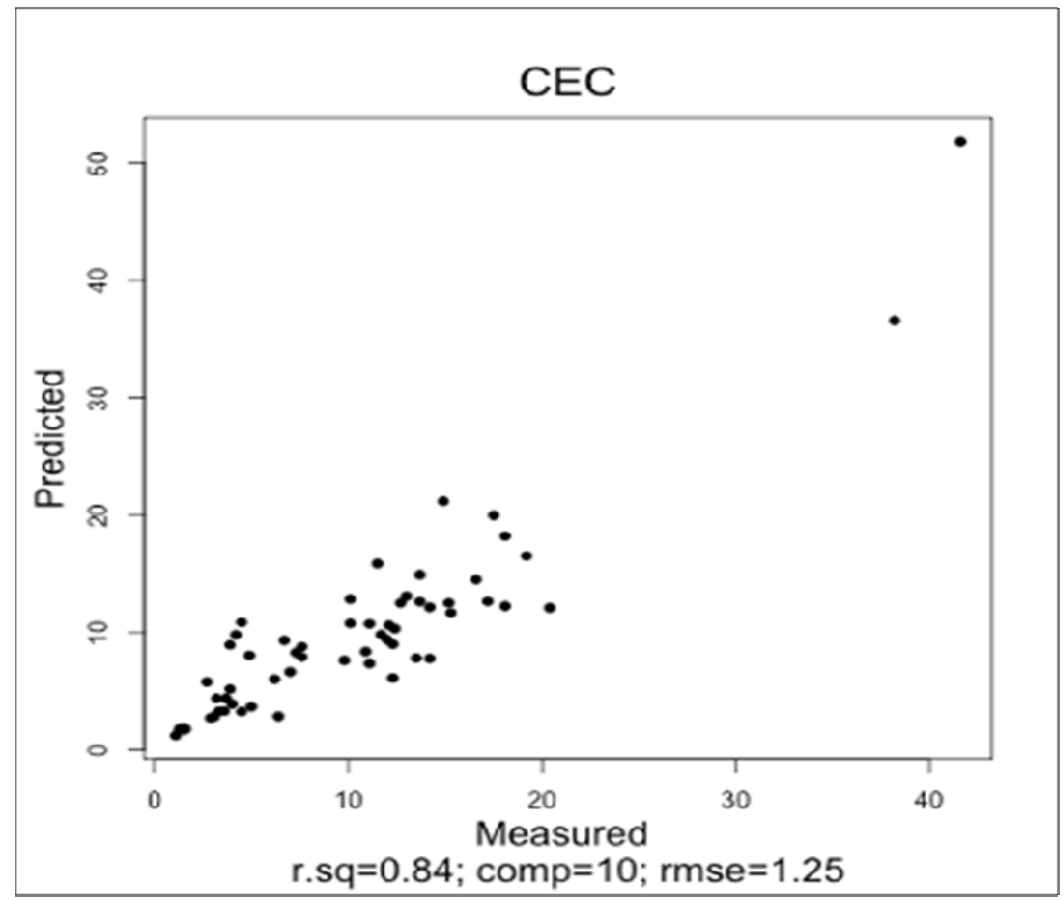

Figure 4.9: Correlation between measured and predicted values of CEC

(Shepherd and Walsh, 2002; Chang et al., 2001) of K make the model useful for this parameter.

This is consistent with results of Lark (2009); and Hartemink (2006) who found good prediction of K from 178 samples from Australian landscape. The accuracy of the prediction opens the option of using the estimated values for $\mathrm{K}$ to assess soil state in the region of the study.

\section{Extractable Phosphorus}

Extractable $\mathrm{P}$ was well predicted with $\mathrm{R} 2=0.89$ in this study (Figure 4.8). This implies validation of the model in terms of $\mathrm{P}$ determination. This results match well with those reported by Minasny et al. (2009) in a study conducted for Australian soils. They also agree 
with those of Hartemink (2006) and Madari, et al. (2006) who reported values of $\mathrm{R} 2=0.85$ and 0.93 , respectively from Canada landscape and Sellitto et al. (2009) from India with an R2 of 0.90 .

However, many studies from Canada have reported poor prediction like with an R2 of 0.48 and satisfactory prediction of this parameter; Hartemink (2006) with an R2 of 0.57 , this study gave good prediction as that by Madari et al (2006) from Canada landscape and Sellitto et al. (2009) from India. This is good modeling of $P$ in the eastern of DR Congo opens a new opportunity for assessing this important nutrient of crop production.

\section{Cation Exchangeable Capacity}

The R2 value for the validation of this method for CEC is 0.84 implying that CEC was predicted well (Figure 4.8). As found in many studies Dunn et al. (2002), Sellitto et al. (2009), Richter et al. (2009), MIR provides good predictions for CEC in different regions eg from India, Canada and US, respectively. Pirie et al. (2005) showed similar prediction accuracy for these this parameter for 415 southeastern Australian samples.

For CEC, R2 is 0, 84 (Figure .4.9) in the current study area and this shows that predicted and therefore estimated and direct values for are closer for this parameter. Sellitto et al. (2009), from India, got also good prediction for this parameter as found with also Pirie et al. (2005) from south Australian soils. This good modeling of CEC is welcome for the soil science research to avoid many constraints associated to traditional laboratory analysis.

\section{Soil physical particles prediction}

Particle size effects on light transmission and reflection, and strong absorption features exhibited by water, explain the accurate predictions for texture (Cécillon et al, 2009; Chang et al., 2001).

Predictions for particle size were satisfactory for clay $(\mathrm{R} 2=0.74$ and $\mathrm{RMES}=1.05)$; sand $(\mathrm{R} 2 ;=0.81$ and RMES $=1.08)$ and silt $(R 2=0.84$ and RMES $=1.06)$. These results are broadly similar to those of previous researchers (McCarty and Reeves, 2006; Pirie et al., 2005). Terhoeven et al, 2010 got similar results globally (clay $(\mathrm{R} 2=0.73$ and RMES $=1.85$ ).

All these tree physical parameters respond to the calibration requirement (Chang et al., 2001; Shepherd and Walsh, 2002; Terhoeven et al, 2010) and validation of the results is correct.

\section{CONCLUSION}

The aim of this study was to evaluate a novel approach of soil characterization based on Infrared Scanning (IR) technique and assess its ability to provide rapid and reliable quantification of soil properties. Generally the results showed good and satisfactory prediction model with more than $75 \%$, for all the chemical parameters under study ( $\mathrm{pH}, \mathrm{Al}, \mathrm{P}, \mathrm{N}, \mathrm{Ca}, \mathrm{K}, \mathrm{PSI}$, Exchangeable acidity, CEC) as well as for soil physical properties. Among the parameters under study, phosphorus gave the best prediction with $\mathrm{R} 2=0.93$, while the others gave R2 higher than 0.75 except SOM and TN which gave R2 $=$ of 0.73 and 0.71 , respectively. The good prediction of all chemical parameters implies that the method of IR scanning is reliable and hence recommended for use in determination of soil properties. In addition the method is fast and economical. Analysis of the 530 samples took 2 days to scan while it could have taken more than 2 months with the conventional methods of soil analysis. Soil particles prediction was also good for all the three parameters, with $\mathrm{R} 2=, 0.81 ; 0.84$ and 0.74 for sand, silt and clay, respectively. This is an implication that the infrared Scanning technique is reliable for determination of soil texture.

However, this approach is still new and not many scientists have been able to use it. This method cannot also be used alone without the combination of wet chemistry results even at low level. More efforts are needed to improve the use of IR scanning in monitoring soil and land degradation across developing countries. Though IR is cheap for analyzing soil properties it requires high investment at the beginning. There is therefore need of technical and material support to make this technology useful in developing countries.

\section{REFERENCES}

Barthe BG, Brunet D, Hien E, Enjalric F, Conche S, Freschet GT, d'Annunzio R, Toucet-Louri J (2008). Determining the distributions of soil carbon and nitrogen in particle size fractions using nearinfrared reflectance spectrum of bulk soil samples. Soil Biol. Biochem, 40: 1533-1537.

Brown DJ, Bricklemyer RS, Miller PR(2005). Validation requirements for diffuse reflectance soil characterization models with a case study of VNIR soil C prediction in Montana. Geoderma, 129: 251-267.

Brus DJ, de Gruijter JJ, Breeuwsma A(2002). Strategies for updating soil surveyinformation, a case study to estimate phosphate sorption characteristics. Journal of Soil Science 43, 567-581.

Carter MR(2002). Soil quality for sustainable land management: Organic matter and aggregation interactions that maintain soil functions. Agron. J., 94: 3 8-47.

Cécillon L, Cassagne N, Czarnes S, Gros R, Vennetier M, Brun $J J(2009)$. Predicting soil quality indices with near infrared analysis in a wildfire chronosequence. Science of the Total Environment, 407: 1200-1205.

Chang CW, Laird DA, Mausbach MJ, Hurburgh CR(2001). Nearinfrared reflectance spectroscopy-principal components regression analyses of soil properties. Soil Science Society of America Journal, 65: 480-490.

Christy CD(2009). Real-Time Measurement of Soil Attributes Using Onthe-go Near Infrared Reflectance Spectroscopy. Computers and Electronics in Agriculture, 61:10-19.

Cozzolino D, Moro'n A(2006). Potential of near-infrared reflectance 
spectroscopy and chemometrics to predict soil organic carbon fractions. Soil Tillage Res, 85: 78 85.

Denef K, Plante AF, Six J(2009). Characterization of soil organic matter. Pages 91_126 in W. Kutsch, M. Bahn and A. Heinemeyer, eds. Soil carbon dynamics: An integrated methodology. Cambridge University Press, London, UK.

DSRP. (2005). Document de Strategie de Reduction de la Pauvrete. Province du Sud-Kivu. Republique Démocratique du Congo, Ministère du Plan, Unité de Pilotage de Processus du DSRP, Kinshasa. p96.

Dunn BW, Beecher HG, Batten GD, Ciavarella S(2002).Thepotentialofnear-infraredreflectance spectroscopy for soil analysis a case study from south-eastern Australia. Australian Journal of Experimental Agriculture, 42, 607-614.

Farrow A, Businye L, Bugenze $P(2006)$. Characterisation of Mandate Areas for consortium for improving Agriculture based Livelihoods in Central Africa: pp 138.

Hartemink $A E(2006)$. Assessing soil fertility decline in the tropics using soil chemical data. Advances in Agronomy, 89: 179-225.

ICRAF. (2009). Soil Mid Infrared spectroscopy. ICRAF, NAIROBI.

Jaber N, Mehanna S, Sultan J(2009): Determination of ammonium and organic bound nitrogen by inductively coupled plasma emission spectroscopy. Talanta, 78 (4-5) 1298-1302.

Janik L, Skjemstad J, Shepherd K, Spounce L(2007). Prediction of soil carbon fractions using mid-infrared-partial least square analysis. Australian Journal of Soil Research, 45, 73-81.

Lark $\mathrm{RM}(2009)$. Kriging a soil variable with a simple non-stationary variance model, J. Agric. Biol.Env. Stat., 14, 301-321.

Madari BE, Reeves JB, Machado PL, Guimara es CM, Torres E, McCarty GW(2006). Midand near-infrared spectroscopic assessment of soil compositional parameters and structural indices in two Ferralsols. Geoderma, 136: 245-259.

Mateso W, Nyamugwabiza I, Mabiala-ma-Khete(1998). Programme national de relance du secteur agricole et rural (PNSAR) 19972001. Monographie de la province du Sud-Kivu. Ministères de l'agriculture et de l'élevage, du plan, de l'éducation nationale et de l'environnement, conservation de la nature, forets et peche, Kinshasa. p160

McCarty GW, Reeves IJ(2006). Comparison of near infrared and mid infrared diffuse refl ectance spectroscopy for fi eld-scale measurement of soil fertility parameters. Journal of Soil Science, 171:4-102.

Mevik BH, Wehrens R(2007). The pls package: Principal component and partial least squares regression in $\mathrm{R}$. Journal of Statistical Soft ware, $18: 1-24$.
Minasny B, Tranter G, McBratney A, Brough M, Murph M(2009). Regional transferability of mid-infrared diffuse reflectance spectroscopic predictionfor soil chemical properties. Geoderma, 153: 155-162.

Naess T, Isaksson T, Fearn T, Davies T(2002). A User-friendly Guide to Multivariate Calibration and Classification. NIR publications: Chichester, UK, (provide page number ??????)

Pirie A, Balwant S, Kamrunnahar I(2005). Ultra-violet, visible, nearinfrared, and mid-infrared diffuse refl ectance spectroscopic techniques to predict several soil properties. Aust. J. Soil Res, 43:713-721.

Reeves JB, Follett RF, McCarty GW, Kimble JM(2006). Can near or mid-infrared diffuse reflectance spectroscopy be used to determine soil carbon pools? Commun. Soil Sci. Plant Anal., 37: 2307-2325.

Reeves JB; McCarty GW, Meisinger JJ(1999). Near infrared reflectance spectroscopy for the analysis of agricultural soils. J. Near Infrared Spectroscopy, 9 (1): 25-34.

Richter N, Jarmer T, Chabrillat S, Oyonarte C, Hostert P, Kaufmann $H(2009)$. Freeiron oxide determination in Mediterranean soils using diffuse reflectance spectroscopy. Soil Science Society of America Journal, 73: 72-81.

Sellitto VM, Fernandes RB, Barrón V, Colombo CM(2009). Comparing two different spectroscopic techniques for the characterization of soil iron oxides: diffuse versus bi-directional reflectance. Geoderma, 149: 2-9.

Shepherd K, Walsh M(2002). Development of reflectance spectral libraries for characterization of soil properties. Soil Sci. Soc. Am. J., 66:988-998.

supply in irrigated rice domains of Asia. Agronomy Journal, 95:913-923.

Terhoeven T, Vagen T, Spaargaren O, Shepherd K(2010). Prediction of Soil Fertility Properties from a Globally Distributed Soil MidInfrared Spectral Library. Science Society of America Journal, 74:1792-1799.

Tillmann $T(2000)$. Kalibrationsentwicklung für NIRS-Geräte.CuvillierVerlag, Göttingen, Germany.

Vagen T, Shepherd K, Walsh M, Winowiecki L, Desta L, Tondoh J(2010). AfSIS Technical Specifications Soil Health Surveillance. Africa Soil Information Service. p18.

ViscarraRossel R, Walvoort D, McBratney AB, Janik LJ, Skjemstad $\mathrm{JO}(2006)$. Visible, near infrared, mid infrared or combined diffuse reflectance spectroscopy for simultaneous assessment of various soil properties. Geoderma, 131(1-2), 59-75. 